\title{
A visão dos professores quanto ao processo de ensino e de aprendizagem do basquetebol nas aulas de Educação Física: a realidade de Volta Redonda/RJ
}

\author{
Cláudio Delunardo Severino* \\ Francisco José Miranda Gonçalves** \\ Suraya Cristina Darido***
}

\begin{abstract}
Resumo: A presente pesquisa teve como objetivo geral investigar a visão dos professores acerca do processo de ensino e de aprendizagem do basquetebol nas aulas de Educação Física em ambiente escolar. Participaram da pesquisa docentes das instituições públicas e privadas do município de Volta Redonda/RJ/Brasil em turmas do $6^{\circ}$ ao $9^{\circ}$ ano do ensino fundamental. Tratou-se de um estudo quantiqualitativo com análise de conteúdo e, como procedimento de coleta de dados, foram entrevistados sessenta docentes que opinaram acerca da questão investigada. Verificou-se a realidade do desenvolvimento do basquetebol não somente na condição de conteúdo das aulas da Educação Física, mas também numa dimensão que transpõe os limites escolares, onde o esporte representa significativo papel na sociedade. Ações conjuntas no sentido de oportunizar o crescimento do basquetebol como conteúdo das aulas de Educação Física podem representar um caminho para a descrição da sua aplicação em todos os contextos, embora não se deva abrir mão da relevância da disciplina no cenário escolar em favor da obtenção de resultados em competições esportivas.
\end{abstract}

Palavras-chave: Escola. Basquetebol. Ensino fundamental e médio. Aprendizagem.

\footnotetext{
*Curso de Educação Física do Centro Universitário de Volta Redonda (UniFOA). Volta Redonda, RJ, Brasil E-mail: claudiodelunardo@gmail.com

${ }^{* *}$ Curso de Pós-graduação em Ciências da Educação Física e Desporto. Universidade de Trás-os-Montes e Alto Douro. Portugal. Instituto Superior da Maia, Portugal. E-mail: franciscojmg@gmail.com

***Departamento de Educação Física. Instituto de Biociências. Universidade Estadual Paulista, Campus de Rio Claro, Rio Claro, SP, Brasil. E-mail: surayacd@rc.unesp.br
} 


\section{INTRODUÇÃo}

A se considerarem os últimos resultados em competições internacionais, como, por exemplo, campeonatos mundiais, Jogos Pan-Americanos e Jogos Olímpicos (RODRIGUES; DARIDO, 2012), percebe-se que o basquetebol brasileiro não atravessa um bom momento, não conseguindo repetir o desempenho obtido em anos anteriores, fato que indica certa carência de novos valores, além de problemas acerca da própria estrutura organizacional da modalidade.

Em algumas ocasiões, dirigentes esportivos e técnicos declaram abertamente que a Educação Física pode ser a responsável pela transformação dessa realidade. Tal opinião ganhou ênfase a partir dos Jogos Olímpicos de Sidney, em 2000, quando a proposta da obrigatoriedade da Educação Física nas escolas, que seria fundamental para transformar o Brasil em um "país olímpico", ganhou força a ponto de ser incluída a palavra "obrigatória" quando se menciona a presença da Educação Física no currículo da Educação Básica na Lei de Diretrizes e Bases da Educação Nacional - LDB 9394/96 (BRACHT, 2009). Entretanto, nem sempre se leva em conta o fato de que essa disciplina deve priorizar o desenvolvimento global da criança, e não a formação de desportistas.

A pensar no basquetebol como conteúdo presente nas aulas de Educação Física e quanto ao papel desempenhado pela escola no contexto da prática esportiva, Kanters et al. (2012) afirmam que esta é vista como a principal instituição para promover o contato dos jovens com o esporte, já que se faz presente em praticamente todas as comunidades, a frequência é obrigatória e, além disso, há quase sempre a assistência de professores especializados. No mesmo contexto, Dudley et al. (2012) lembram que as escolas são reconhecidas como as instituições mais utilizadas e com o menor custo para a promoção de atividades físicas.

Nesta mesma linha, Marques (2004) observa que a prática esportiva nas aulas de Educação Física representa uma possibilidade

Movimento, Porto Alegre, v. 20, n. 4, p. 1283-1304, out./dez. de 2014. 
A visão dos professores quanto ao processo de ensino ...

de renovação da educação, a partir do instante em que a quebra de rotina concede à escola o dinamismo e o prazer indispensáveis à atividade. Sobre isso, Booth (2009) afirma que, ao se perceber, principalmente, a complexidade do prazer, é na prática do movimento que a prática esportiva se torna mais evidente.

A escolha da modalidade basquetebol deve-se também ao seu importante papel na sociedade mundial e brasileira, onde a relação dessa modalidade com as vivências do esporte na saúde e no lazer alcança tantos seus praticantes como apreciadores. Além disso, o conhecimento sobre o esporte permite a ampliação do olhar sobre diferentes aspectos e práticas do cotidiano, como, por exemplo, o basquetebol de rua, o basquetebol em cadeira de rodas, NBA, WNBA, as diversas animações e filmes sobre a modalidade em questão.

Todas essas manifestações compõem a cultura do basquetebol, são acontecimentos, fatos, datas, conhecimentos, vivências, práticas, valores construídos ao longo do tempo, trata-se de um rico patrimônio produzido pela humanidade e que acreditase ser indispensável preservar e transmitir às novas gerações (RODRIGUES; DARIDO, 2012).

O presente artigo é integrante de uma pesquisa mais abrangente que pretendeu investigar a visão dos professores quanto ao processo de ensino e de aprendizagem do basquetebol nas aulas de Educação Física em ambiente escolar no município de Volta Redonda - RJ, bem como a sua prática por meninas. Na referida pesquisa, a parte associada a este artigo intenciona averiguar a opinião dos docentes quanto ao desenvolvimento do basquetebol e como a Educação Física Escolar pode atuar neste contexto. Trata-se de um estudo quanti-qualitativo no qual se almeja a compreensão da realidade e ser investigada, bem como a sua interpretação (SILVA et al., 2009). O estudo justifica-se, além da sua importância como produção de conhecimentos voltados para a área da Educação Física Escolar, pela relevância acerca da sua contribuição ao desenvolvimento global dos discentes.

Movimento, Porto Alegre, v. 20, n. 4, p. 1283-1304, out./dez. de 2014. 


\section{Materiais e mÉtodos}

\subsection{PARTICIPANTES}

Participaram da pesquisa licenciados em Educação Física, efetivos dos quadros docentes das instituições de ensino de Volta Redonda e que lecionam nas turmas de $6^{\circ}$ ao $9^{\circ}$ ano do ensino fundamental. $\mathrm{O}$ número de sujeitos participantes foi de 60 professores de ambos os sexos, o que representa $46.87 \%$ dos docentes que atuam nas escolas com ensino fundamental situadas no município.

Salienta-se que os participantes da pesquisa cumpriram com todos os procedimentos necessários de acordo com o Comitê de Pesquisas em Seres Humanos do Centro Universitário de Volta Redonda - UniFOA, ao qual foi submetido o projeto.

\subsection{Procedimentos}

Comoinstrumento de coleta de dados, utilizou-seuma entrevista semiestruturada, contendo duas perguntas: a) Qual a sua visão sobre o processo de ensino e de aprendizagem do basquetebol? b) Como a Educação Física Escolar pode contribuir para este processo? Além da entrevista, utilizou-se uma ficha contendo questões associadas ao campo de ação e características que envolvem o histórico acadêmico dos entrevistados. Para tal, as questões foram: a) Atua em qual rede de ensino? b) Qual a sua titulação? Foram registradas entrevistas com 39 professores do sexo masculino e 21 do sexo feminino, com duração média de seis minutos. Após a realização das entrevistas, os dados coletados foram transcritos para posterior análise (FERREIRA; MORAES, 2012).

A considerar que o gravador oportuniza a coleta das respostas dadas pelos participantes sem que se perca qualquer dado, para a realização das entrevistas, o equipamento utilizado foi um aparelho digital Sony ICD-PX312F $2 G B$.

Movimento, Porto Alegre, v. 20, n. 4, p. 1283-1304, out./dez. de 2014. 


\subsection{INSTRUMENTO}

Para a validação do instrumento de coleta de dados, obedeceuse a dois procedimentos. No primeiro momento, o instrumento foi validado por cinco professores com conhecimento reconhecido sobre a área de estudo e com experiência voltada para a validação de instrumentos de coleta de dados, que sugeriram e orientaram modificações no sentido de tornar o guia de entrevista mais objetivo e coerente com o objetivo do estudo. Após esse procedimento, e para testar a confiabilidade do instrumento, o mesmo foi submetido a um teste-piloto, o qual foi aplicado junto a oito professores de Educação Física (13.33\% dos participantes) com conhecimento e experiência com Educação Física Escolar. Posteriormente, foi solicitado aos professores que apresentassem sugestões no que tange ao grau de compreensão das perguntas, tempo de aplicação da entrevista e acréscimo ou retirada de questões. Essa solicitação teve como objetivo a apuração da qualidade do instrumento, bem como a percepção de uma possível adequação do procedimento de coleta de dados.

\section{Método}

Por meio das transcrições, as informações colhidas foram submetidas a uma análise de conteúdo pelo programa NVIVO 10, software especificamente projetado para vertificar os dados qualitativamente, realizando-se posteriormente uma análise interpretativa dos resultados a partir do referencial teórico utilizado, com o intuito de se obter as porcentagens de ocorrência e os resultados de frequência. Baseando-se no procedimento apresentado por Boyle et al. (2008) em seus estudos, foram utilizadas no processo de análise de conteúdo as seguintes etapas:

- Após serem transcritos para um arquivo de texto, os dados foram lidos e organizados.

- Os dados coletados foram devidamente codificados em categorias previamente identificadas de acordo com os temas vinculados aos docentes entrevistados.

Movimento, Porto Alegre, v. 20, n. 4, p. 1283-1304, out./dez. de 2014. 
Conforme mencionado anteriormente, o presente estudo baseou-se em categorias analíticas, as quais apresentam como componente principal o objeto de estudo. Conforme Bardin (2011) e Souza Junior et al. (2010), torna-se relevante a análise dessas caregorias, em função da apresentação sobre o que se deseja investigar. As categorias foram ramificadas conforme o exposto na Figura 1.

Figura 1 - Modelo de identificação das categorias analíticas para conhecimento do objeto de estudo

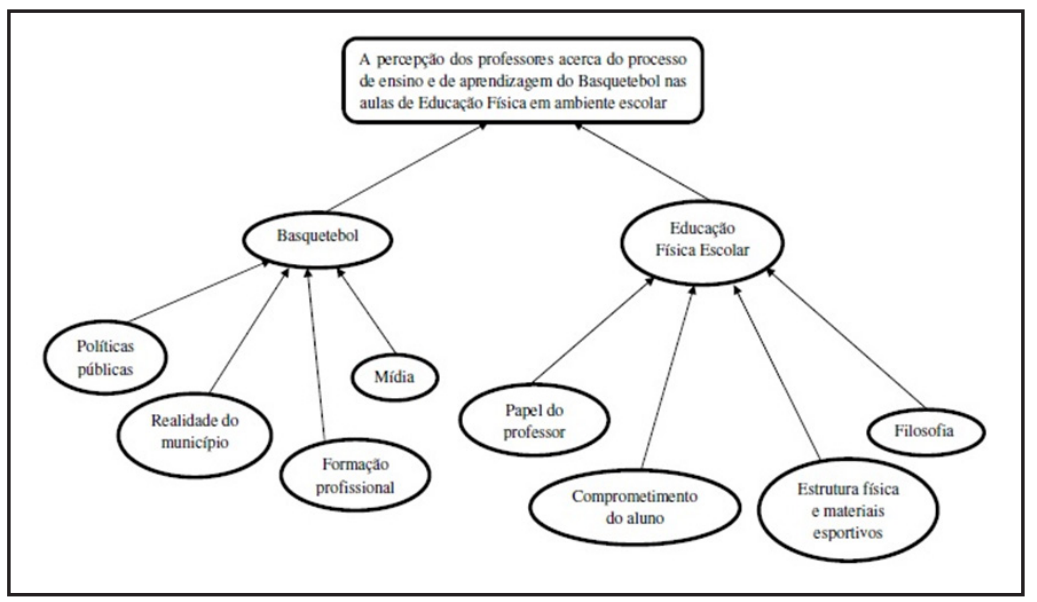

Fonte: (BARDIN, 2011; SOUZA JUNIOR et al., 2010)

\section{Apresentação E discussão dos RESUltados}

Para a garantia do anonimato dos sujeitos entrevistados, os seus respectivos nomes foram substituídos pelo código $\mathrm{P}$, seguido do número de identificação da entrevista, por exemplo, P 1, P 2 e assim sucessivamente.

Dos professores que responderam ao questionário, 46 lecionam na rede pública de ensino $(76,7 \%)$. São docentes na rede privada 11 entrevistados (18,3\%). Observa-se também que, dos professores

Movimento, Porto Alegre, v. 20, n. 4, p. 1283-1304, out./dez. de 2014. 
A visão dos professores quanto ao processo de ensino ...

participantes da pesquisa, 3 lecionam em ambas as redes (5\%). Percebe-se a distinção dos entrevistados que atuam na rede pública em dois grupos, sendo que $33(72 \%)$ dos professores estão vinculados à rede municipal, enquanto $13(28 \%)$ à rede estadual de ensino.

Acerca da qualificação dos docentes entrevistados, houve uma incidência maior de especialistas $(48,4 \%)$ em relação ao percentual de graduados $(38,3 \%)$ e mestres $(13,3 \%)$.

Além da caracterização da amostra, analisou-se posteriormente outra categoria associada ao objetivo do estudo. Os resultados com a incidência das respostas relacionadas à mesma são apresentados na Tabela 1.

Tabela 1 - Incidências das respostas apresentadas.

\begin{tabular}{lcc}
\hline CATEGORIAS & FREQUÊNCIA & $\%$ \\
\hline Papel do professor & 48 & 80 \\
Mídias & 10 & 16.6 \\
Realidade local & 9 & 15 \\
Planejamento curricular & 8 & 13.3 \\
Estrutura física e materiais esportivos & 6 & 10 \\
Políticas públicas & 5 & 8.3 \\
Comprometimento do aluno & 5 & 8.3 \\
Diretrizes Metodológicas & 4 & 6.6 \\
Formação continuada & 4 & 6.6 \\
\hline
\end{tabular}

Fonte: Dados da pesquisa dos autores

Dos entrevistados, 48 (80\%) destacaram a relevância do papel do professor na condição de mediador entre o aluno e os conteúdos da Educação Física, especificamente o basquetebol. Para os participantes da pesquisa, a ação docente é o principal alicerce na construção do conhecimento e na promoção de estímulos que propiciem o desenvolvimento integral dos discentes. Quanto ao processo de ensino e de aprendizagem do basquetebol, a responsabilidade do professor foi apontada como primordial para o seu desenvolvimento.

Movimento, Porto Alegre, v. 20, n. 4, p. 1283-1304, out./dez. de 2014. 
O professor tem a obrigação de não deixar essa modalidade de lado, promover adaptações para que o basquete possa ser praticado (P 3).

Não obstante, constata-se que, em certas ocasiões, o professor de Educação Física, por não ter afinidade com um determinado conteúdo, não releva as necessidades dos alunos no sentido de propiciar a estes uma diversificação de experiências motoras (LEITE; SAMPAIO, 2012). Por intermédio do seu conhecimento e de suas ações pedagógicas, o professor deve, diante deste cenário, despertar nos alunos a consciência de que a prática do basquetebol pode favorecer não somente o desenvolvimento dessa modalidade, mas também proporcionar satisfação, melhoria da qualidade de vida e outros fatores que venham a contribuir para o seu desenvolvimento global.

Então às vezes as pessoas arrumam artifícios para não trabalhar certos conteúdos. Tem profissional que fala "eu não gosto de basquete", e por isso eu não trabalho este conteúdo. Eu não tenho que amar, eu tenho que fazer da melhor forma possível! Eu tenho material, eu tenho espaço disponível, eu tenho alunos que gostam (P 11).

A Educação Física, a partir das ações do professor, pode, segundo as observações feitas pelos participantes, oportunizar um primeiro contato com o basquetebol e, talvez, iniciar naquele momento uma grande identificação do aluno com a modalidade. Não fazê-lo, segundo Vianna e Lovisolo (2009), torna-se um equívoco, mesmo a considerar as incoerências e inadequações presentes no esporte em geral.

Foi mencionada por 10 professores participantes $(16,66 \%)$ como um entrave para o desenvolvimento do basquetebol no Brasil a pequena participação da mídia, em função da baixa incidência de transmissões televisivas em canais abertos e notícias veiculadas na imprensa envolvendo essa modalidade e os seus principais atletas. Esse fato, segundo os professores, prejudica a massificação do basquetebol no Brasil e, consequentemente, a descoberta de valores.

Movimento, Porto Alegre, v. 20, n. 4, p. 1283-1304, out./dez. de 2014. 
Oque a gente encontraé o fato de que o basquetebol no Brasil não é fomentado, talvez tanto quanto o futsal, futebol ou até mesmo o vôlei. Isso faz com que os alunos culturalmente não convivam com o basquete com tanta frequência (P 4).

Em se tratando de transmissões televisivas, o telespectador estabelece um vínculo com a realidade esportiva, o que pode consumar uma aproximação com determinadas modalidades. Entretanto, essa aproximação pode ser compreendida de duas maneiras. A primeira como uma relação com o esporte apresentado superficialmente com a manifesta intenção de atender aos interesses socioeconômicos de uma minoria hegemônica, o que acarretaria unicamente a formação de significados e a reprodução de técnicas de movimentos a partir do que é apresentado pela mídia (KUNZ, 2009). A segunda forma de aproximação pode ser por meio de uma análise crítica envolvendo todas as perspectivas do esporte, como a participação coletiva, a construção de valores, os significados, a sua prática como melhoria da qualidade de vida, entre outros, fazendo com que a inserção do esporte - o basquetebol - como conteúdo das aulas de Educação Física represente, além da possibilidade da participação efetiva dos alunos nesta modalidade, a valorização de quem se movimenta e não apenas os movimentos executados (RODRIGUES; DARIDO, 2008).

A participação (ou a ausência) da mídia na massificação do basquetebol foi também associada pelos professores entrevistados à notória preferência pelas transmissões de jogos de futebol, principalmente nos canais abertos de televisão, onde há uma desproporcional incidência favorável a esta modalidade em relação às outras. Esse cenário deve-se, possivelmente, além da própria popularização do futebol no Brasil, à satisfação de interesses mercadológicos envolvidos nas transmissões, como já mencionado anteriormente.

Nove professores participantes do estudo (15\%) creditaram o discreto desenvolvimento do basquetebol à realidade do município de Volta Redonda, assim como à pouca importância que é concedida

Movimento, Porto Alegre, v. 20, n. 4, p. 1283-1304, out./dez. de 2014. 
à Educação Física Escolar nesse contexto. As justificativas baseiamse no maior privilégio dado a outras modalidades, na metodologia utilizada pelos professores, na ausência do basquetebol como conteúdo das aulas de Educação Física, na falta de conscientização por parte do poder público municipal quanto a um maior incentivo à prática da modalidade e à formação de equipes competitivas e na falta de professores de Educação Física com um histórico esportivo associado ao basquetebol.

Em relação às questões que, segundo os sujeitos da pesquisa, envolvem a realidade de Volta Redonda, cabem algumas considerações. Primeiramente, ressalta-se que o apoio oferecido por órgãos públicos ou privados a outras modalidades esportivas no município não pode ser considerado excessivo. Atualmente, há em Volta Redonda equipes que disputam competições regionais, nacionais e internacionais no futebol, voleibol, natação, rúgbi, ginástica de trampolim e badminton, sendo que em algumas dessas modalidades prevalece mais o esforço e a dedicação de alguns profissionais do que propriamente o suporte concedido aos seus respectivos projetos, seja de ordem financeira, material ou por meio de divulgação. Quanto ao basquetebol, mesmo que a cidade disponha de vários espaços adequados para a sua prática sistematizada, não ocorre uma mobilização que objetive a sua massificação, formação de equipes e participação em competições, tampouco ações advindas do poder público nesse sentido, independentemente dos projetos vinculados às modalidades mencionadas anteriormente, $\mathrm{o}$ que, para Werle (2010), caracteriza a ausência de ações voltadas para a compreensão e valorização de uma modalidade esportiva.

Sobre a metodologia empregada pelos professores em relação ao processo de ensino e de aprendizagem do basquetebol, observouse a questão do treinamento especializado precoce, situação compreendida como o emprego de procedimentos que objetivam a prática esportiva especializada sem que as crianças ainda estejam devidamente preparadas, objetivando resultados em curto prazo (LEITE; SAMPAIO, 2012; MARQUES, 2004; MENEZES et al., 2014).

Movimento, Porto Alegre, v. 20, n. 4, p. 1283-1304, out./dez. de 2014. 
Os locais onde existe a prática do basquete, onde há a procura por essa modalidade, adotam um trabalho tão intensivo, tão forçado que a criança acaba perdendo o interesse por essa modalidade com o passar do tempo, devido a tanta cobrança por resultados imediatos. Aí chega o período onde deve haver essa cobrança por um melhor desempenho, ele já não quer mais. Eu vejo isso em Volta Redonda! (P 10).

Para Menezes et al. (2014), mesmo que o professor de Educação Física tenha um conceito estruturado sobre os processos que evitem a especialização precoce, em diversas ocasiões isso pode ser conflitante em relação ao campo de intervenção prática e também ao pouco conhecimento sobre a Educação Física e suas particularidades por parte de gestores, fato que pode ocasionar certa pressão sobre os docentes. Neste caso, torna-se relevante a ação do professor quanto à escolha da metodologia mais adequada para o atendimento das necessidades motoras e cognitivas dos alunos.

A respeito da ausência do basquetebol como conteúdo das aulas de Educação Física e a pequena incidência de professores de Educação Física com um histórico esportivo associado a essa modalidade, observa-se que a sua relevância deve ser vista na condição de prática pedagógica e, em se tratando do ambiente escolar, ela deve ser trabalhada de forma abrangente para que possibilite aos discentes o contato com todas as oportunidades vinculadas ao seu desenvolvimento (RODRIGUES; DARIDO, 2008). No que tange aos professores de Educação Física, mesmo que não tenham tido experiências anteriores com o basquetebol, é imprescindível a aquisição de conhecimentos que possibilitem a aplicação dos conteúdos em suas aulas, seja por meio de cursos de capacitação, aperfeiçoamento ou a investigação por intermédio de pesquisas. A vivência esportiva é uma aliada importante para uma boa atuação profissional, mas não pode ser vista como conditio sine qua non para a aplicação de determinados conteúdos nas aulas.

Na perspectiva de 8 professores participantes $(13,33 \%)$, a dificuldade em ter como referência um planejamento curricular

Movimento, Porto Alegre, v. 20, n. 4, p. 1283-1304, out./dez. de 2014. 
contendo diretrizes que contemplem as necessidades dos discentes, não apenas as de ordem motora ou tecnicista, mas as intelectuais e sociais (MENDES; AZEVÊDO, 2010), é apontada como um fator prejudicial para a contribuição da Educação Física Escolar ao processo de ensino e de aprendizagem do basquetebol.

$\mathrm{Eu}$ sinto muita dificuldade em relação a currículo e uma progressão. Geralmente a gente trabalha alguns conteúdos, na rede municipal há aquilo que é chamado de pré-requisitos, a gente trabalha em cima daquilo e acrescenta alguma coisa. Só que você vê o pré-requisito do sétimo, do oitavo ano e percebe que ele é praticamente o mesmo do sexto ano. Não há uma progressão (P 19).

Mesmo que haja um planejamento curricular para as escolas municipais de Volta Redonda, percebe-se na fala acima a inquietação quanto à sua eficácia. Para Pereira e Mendes (2010), uma mudança na forma de organização curricular defronta com princípios e paradigmas daqueles que integram o sistema escolar. Os autores ressaltam que as estratégias utilizadas para a elaboração de um currículo que contemple os anseios da comunidade escolar nem sempre são adequadas em relação aos objetivos que são elencados.

Em relação às condições da estrutura física e a qualidade (e quantidade) de materiais esportivos disponíveis para as aulas de Educação Física, seis professores (10\%) mencionaram a falta de materiais esportivos, especialmente bolas, e, também, a precariedade das instalações esportivas em suas escolas.

O que eu percebo é que, com relação a materiais, a gente já sente dificuldade em trabalhar o basquete. Para se ter ideia, eu trabalhei basquete sem tabela e sem bola de basquete, substituídas por uma bola de vôlei e um balde (P 3).

De tal depoimento sobre a estrutura física e os materiais disponíveis para as aulas de Educação Física surge a reflexão no que concerne a duas questões. A primeira, sobre as condições que os professores de Educação Física dispõem para a realização

Movimento, Porto Alegre, v. 20, n. 4, p. 1283-1304, out./dez. de 2014. 
de um trabalho que, ao menos em sua concepção, almeja ser eficiente. Além disso, questiona-se até que ponto, diante de tais circunstâncias, é possível perceber a Educação Física Escolar como um campo fecundo para o desenvolvimento de uma modalidade esportiva como o basquetebol. É importante observar que, com essas indagações, não se pretende abrir mão de uma Educação Física que oportuniza aos alunos a experiência com uma grande diversidade de materiais alternativos, a prática limitada apenas ao espaço da quadra ou, principalmente, o contato com uma modalidade esportiva não somente de acordo com os parâmetros estabelecidos como "técnica correta", mas sim por meio da vivência das mais diversas formas que o esporte pode ser visto - e revisto -, como, por exemplo, por intermédio da ludicidade e com base em valores como a cooperação e a lealdade. Pretende-se, sim, fomentar a discussão sobre a relevância que se dá à Educação Física Escolar na condição de componente curricular.

No que diz respeito às políticas públicas voltadas para a prática esportiva estudantil, identificou-se que cinco professores $(8,33 \%)$ têm a opinião de que existe uma carência em relação a ações concretas que objetivem um planejamento voltado para o desenvolvimento do esporte. Observa-se que essa concepção, segundo os professores entrevistados, abrange as esferas municipais, regionais e nacionais.

Agora, se você não tem uma política, se não é uma prioridade do governo, seja municipal, estadual ou federal, infelizmente nada irá pra frente, nada. Se não houver um apoio, um desejo, uma vontade por parte de quem tem condições de fazer isso, não serei eu que mudarei alguma coisa em relação a isso (P 43).

$\mathrm{Na}$ condição de direito social, a prática esportiva é direito de cada um e, consequentemente, representa um dever do Estado a promoção de seu fomento (CUI; SU, 2012; MENDES; AZEVÊDO, 2010). As políticas públicas voltadas para essa questão devem estar em consonância com a realidade da cada comunidade, evitando os resultados favoráveis a interesses pessoais em detrimento dos

Movimento, Porto Alegre, v. 20, n. 4, p. 1283-1304, out./dez. de 2014. 
ganhos coletivos, superfaturamentos, vantagens e impunidades (WERLE, 2010).

Há o entendimento de que as políticas públicas devem objetivar principalmente a prática esportiva não formal, no sentido de evitar a reprodução do sistema esportivo que privilegia a seleção e a exclusão (GUIRALDELLI JUNIOR, 2001; KUNZ, 2009; MENDES; AZEVÊDO, 2010; STIGGER, 2009). Não obstante, a política brasileira voltada para a Educação Física e a prática esportiva apresenta, na concepção de Guiraldelli Junior (2001), as características acima mencionadas, onde prevalecem os interesses econômicos aos quais o esporte é subordinado.

No decorrer das entrevistas, cinco docentes (8,33\%) mencionaram a falta de comprometimento dos alunos em relação ao desenvolvimento do basquetebol em ambiente escolar. Para esses professores, percebe-se o que foi considerado como "falta de interesse" por parte dos alunos, fato impulsionado pela motivação em participar de outras atividades que não chegaram a ser mencionadas nos depoimentos.

Bem, a visão que eu tenho é essa questão da boa vontade deles. Acho que fica uma lacuna aí. Acho que o processo fica comprometido porque o aluno não tem boa vontade. Ele faz, mas não se entrega àquilo ali. Eles não têm aquele interesse nato de se entregar especificamente ao basquete. Eles têm outras realidades que eles gostam mais, fazem apenas por obrigação (P 12).

Sobre esse interesse observado pelos professores, ele é em muitas situações motivado por elementos vinculados ao prazer em participar de uma atividade esportiva, o desenvolvimento de habilidades ou, em questões mais específicas, como uma forma de ascensão social (JANUÁRIO et al., 2012; MENEZES et al., 2014). Para Betti e Liz (2003), é notória a intervenção das motivações voltadas para o esporte nas aulas de Educação Física de acordo com um enfoque esportivo, pois nota-se, por parte do aluno, a percepção do esporte como necessidade fundamental,

Movimento, Porto Alegre, v. 20, n. 4, p. 1283-1304, out./dez. de 2014. 
pois, por intermédio da sua prática, o discente libera energia, diminui as tensões, se conhece melhor, apresentando assim um desenvolvimento quanto à sua relação consigo e com o meio. Barkoukis et al. (2010) interpretam o comportamento do aluno como resultado da conjunção entre a sua capacidade, o meio ambiente e a satisfação das suas necessidades.

Entretanto, constata-se que a falta de comprometimento dos alunos mencionada pelos professores pode estar associada à ausência de motivação ocasionada pela diminuição do interesse em participar de atividades em grupo, à falta de necessidade em se aprimorar em relação à técnica específica de uma modalidade esportiva como o basquetebol ou à inexistência de metas a serem cumpridas no contexto onde ocorreu a presente investigação. Januário et al. (2012) afirmam que uma falta de comprometimento por parte dos alunos em relação à prática esportiva pode estar vinculada às características demográficas presentes na população, como, por exemplo, o nível socioeconômico, a faixa etária, as características culturais, a etnia, entre outras variáveis.

Quatro professores $(6,66 \%)$ apontaram a necessidade de se definir ações a serem concretizadas com o intuito de se estabelecer uma coerência quanto ao desenvolvimento do basquetebol como conteúdo das aulas de Educação Física. Essas ações, segundo os professores que abordaram a questão, baseiam-se na construção coletiva de uma metodologia que almeje a definição de como o basquetebol deve ser aplicado, desde a escola até as seleções nacionais. Os princípios metodológicos do incremento do basquetebol nas aulas de Educação Física que foram mencionados baseiam-se na construção de uma linha de ação vinculada a uma padronização do ensino da referida modalidade, sem a desvalorização da função da Educação Física como componente curricular (AKTOP; KARAHAN, 2012).

$\mathrm{Eu}$ penso que nós ainda estamos buscando uma identidade, ainda falta uma linha de ação, como nós queremos jogar e fazer com esse estilo de jogo chegue até as escolas, através das federações, confederação, ligas, etc., para que

Movimento, Porto Alegre, v. 20, n. 4, p. 1283-1304, out./dez. de 2014. 
nós, professores, trabalhemos essa maneira de jogar basquete no Brasil (P 2).

Em se tratando de diretrizes voltadas para a construção de um conjunto de ações voltado para o processo de ensino e de aprendizagem do basquetebol, Xianjiang et al. (2012) consideram que este deva compactuar com as características sociais, econômicas e políticas do contexto no qual está inserido. A considerar tal afirmação, almejar diretrizes metodológicas com o intuito de fomentar o basquetebol significa a necessidade da compreensão dos mecanismos públicos e privados direcionados à educação em um país onde os interesses individuais, a má utilização do dinheiro público e a utilização de meios ilícitos por parte dos gestores (municipais, estaduais e federais) para se alcançar determinadas vantagens possuem características endêmicas.

Pensar em um basquetebol praticado com a mesma filosofia desde o espaço escolar até as seleções nacionais pode representar uma proposta viável, desde que prevaleçam os objetivos voltados para os resultados coletivos, bem como a própria função da Educação Física Escolar. Nesse sentido, a escola é percebida como um espaço para a massificação da modalidade, fortalecendo a harmonia entre a prática do basquetebol e a educação integral do aluno (XIANJIANG et al., 2012). Observa-se que o êxito da construção dessa linha de ação só será possível mediante a garantia de acesso à prática do basquetebol por todos, independentemente de questões como gênero, raça ou condição social.

Os participantes da pesquisa manifestaram opiniões a respeito da formação continuada dos professores de Educação Física. Nesse sentido, três entrevistados (5\%) expuseram críticas em relação a essa questão ao apontarem que o professor recém-formado sai do Curso de Educação Física possuindo um conjunto de informações voltadas para as diversas áreas de conhecimento. Todavia, na visão dos entrevistados, a maioria desses professores não procura uma formação continuada voltada para a especialização do basquetebol, seja por intermédio de cursos de especialização ou períodos de

Movimento, Porto Alegre, v. 20, n. 4, p. 1283-1304, out./dez. de 2014. 
acompanhamento de trabalhos realizados por profissionais mais experientes.

O estudo realizado por Pereira e Hunger (2003) indica que uma possível solução para a melhoria da realidade acima observada é o oferecimento de possibilidades voltadas para a formação permanente do professor. Conforme mencionado anteriormente, os cursos de especialização e a investigação são fundamentais, tendo em vista que a licenciatura não apresenta como objetivo a formação de técnicos que conduzirão trabalhos voltados para a aquisição de resultados em competições. Entretanto, mesmo que as experiências e conhecimentos especializados adquiridos em cursos de extensão contribuam para o desenvolvimento do basquetebol, ressalta-se a necessidade da compreensão do papel da Educação Física Escolar nesse contexto, que é tratar do esporte como manifestação corporal, sempre o respeitando como um conteúdo das aulas.

\section{Conclusões}

No decorrer do estudo, procurou-se investigar a percepção dos professores acerca do processo de ensino e de aprendizagem do basquetebol nas aulas de Educação Física em ambiente escolar realizadas no município de Volta Redonda.

As declarações dos participantes da pesquisa possibilitaram a identificação da realidade do desenvolvimento do basquetebol não somente na condição de conteúdo das aulas, mas também numa dimensão que transpõe os limites escolares, onde o esporte representa significativo papel na sociedade. Considerações acerca do comportamento da mídia e a realização de políticas públicas são exemplos de como esporte pode fomentar discussões que transcendem aspectos associados apenas às características específicas de cada modalidade.

Sobre a importância do professor de Educação Física no que tange ao seu compromisso com a prática pedagógica, percebeu-se que os depoentes consideram a ação docente como o arcabouço

Movimento, Porto Alegre, v. 20, n. 4, p. 1283-1304, out./dez. de 2014. 
para a percepção das necessidades dos alunos. Em se tratando do desenvolvimento do basquetebol, o professor, amparado por esse compromisso, deverá propiciar aos discentes a consciência em relação à prática da modalidade, como um caminho voltado para o seu crescimento, além do próprio regozijo que o contato com as situações específicas do jogo poderá lhe proporcionar. Para isso, o docente deve considerar as características culturais dos alunos, entre outras condições que possam favorecer o comprometimento destes com o trabalho realizado nas aulas de Educação Física.

Quanto aos procedimentos metodológicos a serem utilizados nas aulas, competirá ao professor a escolha de ações adequadas para a satisfação das necessidades motoras e cognitivas dos alunos. Para que o seu trabalho apresente resultados voltados para a massificação, formação ou promoção da modalidade tornase relevante a preocupação, por parte dos gestores, em oferecer condições físicas, materiais e econômicas para que as ações se desenvolvam. Nesse caso, a participação do poder público é fundamental, desde que não seja prioridade a utilização do esporte como condição para o atendimento de interesses pessoais.

Ações conjuntas no sentido de oportunizar o crescimento do basquetebol como conteúdo das aulas de Educação Física podem representar um caminho para a descrição da sua aplicação em todos os contextos, embora não se deva abrir mão da relevância da disciplina no cenário escolar em favor da obtenção de resultados em competições esportivas. Ressalta-se que não há por parte deste estudo a intenção de considerar o esporte de rendimento como um elemento contrário aos princípios da Educação Física Escolar, mas sim compreendê-lo como uma ferramenta que possa ser utilizada no sentido de oportunizar aos alunos a construção e a compreensão de valores. 
The vision of teachers regarding teaching and learning of basketball in Physical Education lessons: the reality of Volta Redonda/RJ

Abstract: The present study has as its main purpose the investigation of teachers' view concerning the teaching and learning of basketball in Physical Education classes in a school setting. The selected teachers who participated in this survey come from public and private institutions in the city of Volta Redonda, RJ, Brazil, teaching $6^{\text {th }}-9^{\text {th }}$ grade classes of elementary school. This was a quantitative and qualitative study with content analysis. Data collection included interviewing 60 teachers who provided their opinions on the issue investigated. Development of basketball was investigated not only as a content for the Physical Education classes, but also as a dimension that goes beyond school boundaries, where that sport plays an important role in society. Joint actions to provide the opportunity for basketball to grow as a content for Physical Education classes may represent a way to describe its implementation in all contexts, although the importance of this discipline in the school setting should not be disregarded in favor of obtaining results in sports competitions.

Keywords: School. Basketball. Education, primary and secondary. Learning.

La visión de los profesores en cuanto al proceso de enseñanza y aprendizaje del basquetbol en las clases de Educación Física: la realidad de Volta Redonda/RJ

Resumen: La presente investigación tuvo como objetivo general explorar la visión de los profesores acerca del proceso de enseñanza y aprendizaje del Basquetbol en las clases de Educación Física en ambiente escolar. Participaron en la investigación docentes de las instituciones públicas y privadas del municipio de Volta Redonda/ RJ/Brasil en cursos del $6^{\circ}$ al $9^{\circ}$ año de la Enseñanza Fundamental. Se trató de un estudio cuanti-cualitativo con análisis de contenido y, como procedimiento de recopilación de datos, fueron entrevistados sesenta docentes que opinaron acerca de la cuestión investigada. Se estudió la realidad del desarrollo del Basquetbol no sólo en la condición de contenido de las clases de Educación Física, sino también en una dimensión que sobrepasa los límites escolares, donde el deporte representa significativo papel en la sociedad. Acciones conjuntas en el sentido de favorecer el crecimiento del Basquetbol como contenido de las clases de Educación Física pueden representar un camino para llegar a la descripción de su aplicación en todos los contextos, aunque no se deba olvidar la relevancia de la disciplina en el escenario escolar en favor de la obtención de resultados en competiciones deportivas.

Palabras clave: Escuela. Basquetbol. Enseñanza fundamental y media. Aprendizaje. 


\section{REFERÊNCIAS}

AKTOP, Abdurrahman; KARAHAN, Nilüfer. Physical education teacher's views of effective teaching methods in physical education. Procedia - Social and Behavioral Sciences, Leuisville, v. 46, p. 1910-1913, 2012.

BARDIN, Laurence. Análise de conteúdo. São Paulo: Edições 70, 2011.

BARKOUKIS, Vassilis et al. Extending the trans-contextual model in physical education and leisure-time contexts: Examining the role of basic psychological need satisfaction. British Journal of Educational Psychology, London, v. 80, n. 4, p. 647-670, 2010.

BETTI, Mauro; LIZ, Marlene Terezinha Facco. Educação física escolar: a perspectiva de alunas do ensino fundamental. Motriz, Rio Claro, v. 9, n. 3, p. 135142, set./dez. 2003.

BOOTH, Douglas. Politics and pleasure: the philosophy of physical education revisited. Quest, London, v. 61, n. 2, p. 133-153, 2009.

BOYLE, Spencer Earl; JONES, Georgina L.; WALTERS, Stephen J. Physical activity among adolescents and barriers to delivering physical education in Cornwall and Lancashire, UK: A qualitative study of heads of PE and heads of schools. BMC Public Health, Bethesda, v. 8, p. 273, 2008.

BRACHT, Valter. Sobre mal-entendidos e equívocos II. In: Esporte de rendimento e esporte na escola. STIGGER, M. P.; LOVISOLO, H. Esporte de rendimento e esporte na escola. Campinas: Autores Associados, 2009. p. 173-178.

CUI, Ruixue; SU, Lina. Research status on equalization of public sports service for nationwide fitness in Hebei. Physics Procedia, Cambridge, v. 25, p. 2298-2303, 2012.

DUDLEY, Dean A. et al. Changes in physical activity levels, lesson context, and teacher interaction during physical education in culturally and linguistically diverse Australian schools. International Journal of Behavioral Nutrition and Physical Activity, London, v. 9, p. 114, 2012.

FERREIRA, Renato Melo; MORAES, Luiz Carlos de. Influência da família na primeira fase de desenvolvimento da carreira de nadadores medalhistas olímpicos brasileiros. Motricidade, Porto, v. 8, n. 2, p. 42-51, 2012.

GHIRALDELLI JUNIOR, Paulo. Educação física progressista: a pedagogia crítico-social dos conteúdos e a educação física brasileira. 7.ed.. São Paulo: Loyola, 2001.

JANUÁRIO, Nuno et al. Motivação para a prática desportiva nos alunos do ensino básico e secundário: influência do Gênero, idade e nível de escolaridade. Motricidade, Porto, v. 8, n. 4, p. 38-51, 2012.

KANTERS, Michael et al. School sport participation under two school sport policies:

Movimento, Porto Alegre, v. 20, n. 4, p. 1283-1304, out./dez. de 2014. 
A visão dos professores quanto ao processo de ensino ...

comparisons by race/ethnicity, gender, and socioeconomic status. The Society of Behavioral Medicine, Milwaukee, v. 47, n. 3, p. 178-194, 2012.

KUNZ, Elenor. Transformação didático-pedagógica do esporte. 7. ed.. ljuí: Unijuí, 2009.

LEITE, Nuno; SAMPAIO, Jaime. Long-Term Athletic Development Across Different Age Groups and Gender from Portuguese Basketball Players. International Journal of Sports Science \& Coaching, Brentwood, v. 7, n. 2, p. 285-300, 2012.

MARQUES, Antonio. Fazer da competição dos mais jovens um modelo de formação e educação. In: GAYA, A.; MARQUES, A.; TANI, G. Desporto para crianças e jovens: razões e finalidades. Porto Alegre, RS: UFGRS. 2004. p. 75-96.

MENDES, Alessandra Dias; AZEVÊDO, Paulo Henrique. Políticas públicas de esporte e lazer \& políticas públicas educacionais: promoção da educação física dentro e fora da escola ou dois pesos e duas medidas?. Revista Brasileira de Ciências do Esporte, Porto Alegre, v. 32, n. 1, p. 127-142, 2010.

MENEZES, Rafael Pombo; MARQUES, Renato Francisco Rodrigues; NUNOMURA, Myrian. Especialização esportiva precoce e o ensino dos jogos coletivos de invasão. Movimento, Porto Alegre, v. 20, n. 1, p. 351-373, jan./mar. 2014.

PEREIRA, Juliana Martins; HUNGER, Dagmar. Formação e atuação profissional no voleibol: opinião de técnicos da cidade de São José dos Campos, SP. Motriz, Rio Claro, v. 9, n. 2, p. 89-96, mai./ago. 2003.

PEREIRA, Neiva; MENDES, Valdelaine da Rosa. A educação física na escola organizada por ciclos de formação: especificidades do trabalho docente. Movimento, Porto Alegre, v. 16, n. 3, p. 109-132, jul./set. 2010.

RODRIGUES, Heitor de Andrade; DARIDO, Suraya Cristina. A técnica esportiva em aulas de educação física: um olhar sobre as tendências sócio-culturais. Movimento, Porto Alegre, v. 14, n. 2, p. 137-154, mai./ago. 2008.

RODRIGUES, Heitor de Andrade; DARIDO, Suraya Cristina. Basquetebol na escola: uma proposta didático-pedagógica. Rio de Janeiro: Guanabara Koogan, 2012.

SILVA, Junior Vagner Pereira da; DAGOSTIN, Kelly Umbelina Deus; NUNEZ, Paulo Ricardo Martins. Educação física e conteúdos trabalhados nas séries iniciais do ensino fundamental. Motriz, Rio Claro, v. 15, n. 3, p. 592-599, jul./set. 2009.

SOUZA JUNIOR, Marcílio Barbosa Mendonça de.; MELO, Marcelo Soares Tavares de; SANTIAGO, Maria Eliete. A análise de conteúdo como forma de tratamento dos dados numa pesquisa qualitativa em educação física escolar. Movimento, Porto Alegre, v. 16, n. 3, p. 31-49, jul./set. 2010.

STIGGER, Marco Paulo. Relações entre o esporte de rendimento e o esporte da escola. In STIGGER, M. P.; LOVISOLO, H. Esporte de rendimento e esporte na escola. Campinas: Autores Associados, 2009. p. 103-134.

Movimento, Porto Alegre, v. 20, n. 4, p. 1283-1304, out./dez. de 2014. 
VIANNA, José Antônio; LOVISOLO, Hugo Rodolfo. Desvalorização da aprendizagem técnica na educação física: evidências e críticas. Motriz, Rio Claro, v. 15, n. 4, p. 883-889, out./dez. 2009.

WERLE, Verônica. Reflexões sobre a participação nas políticas públicas de esporte e lazer. Motriz, Rio Claro, v. 16, n. 1, p. 135-142, jan./mar. 2010.

XIANJIANG, Zhou; BIN, Zong; XIAWU, Wu. Research on development mode of foreign competitive basketball. Physics Procedia, Cambridge, v. 33, p. 2064-2069, 2012.

Endereço para correspondência:

Cláudio Delunardo Severino

Avenida Nove de Julho, no 171

Retiro, Volta Redonda - RJ

CEP 27275-230)

Recebido em: 31.03.2014

Aprovado em: 06.07.2014

Movimento, Porto Alegre, v. 20, n. 4, p. 1283-1304, out./dez. de 2014. 